\title{
Structural and optical properties of a-C:H:O:Cl and a-C:H:Si:O:Cl films obtained by Plasma Enhanced Chemical Vapor Deposition
}

\author{
Isabela Cristina Fernandes ${ }^{a}$, Tayan Vieira Hadich ${ }^{\mathrm{a}}$, \\ Milena Kowalczuk Manosso Amorim ${ }^{\mathrm{a}, 1}$, Rafael Gustavo Turri ${ }^{\mathrm{a}, 1}$, Elidiane C. Rangel a, \\ José Humberto Dias da Silva ${ }^{\mathrm{b}}$, Steven F. Durrant ${ }^{\mathrm{a},{ }^{*}}$ \\ a Laboratório de Plasmas Tecnológicos, Instituto de Ciência e Tecnologia de Sorocaba, Universidade Estadual Paulista (UNESP), Av. Três de Marco 511, Alto de \\ Boa Vista, 18087-180 Sorocaba, SP, Brazil \\ b Laboratório de Filmes Semicondutores, Depto. de Física, Faculdade de Ciências, UNESP, Bauru, SP, Brazil
}

\section{H I G H L I G H T S}

- Amorphous chlorinated plasma polymers produced.

- Stoichiometries of a-C:H:O:Cl and a-C:H:Si:O:Cl varied.

- Tauc gaps varied from 1.3 to $2.6 \mathrm{eV}$.

\section{A R T I C L E I N F O}

\section{Article history:}

Available online 27 April 2018

\section{Keywords:}

Chlorinated plasma polymers

Ultraviolet-visible near infrared

spectroscopy

Optical properties

PECVD

\begin{abstract}
A B S T R A C T
Amorphous hydrogenated oxygenated chlorinated carbon materials with and without silicon were produced by PECVD at deposition rates of up to $150 \mathrm{~nm} \mathrm{~min}^{-1}$. Surface roughness, morphology and contact angle were almost independent of the main system parameter, namely the partial pressure of $\mathrm{CHCl}_{3}$ in the plasma feed, $\mathrm{C}_{\mathrm{Cl}}$. Infrared reflection absorption spectroscopy (IRRAS) of the films revealed the presence of $\mathrm{C}=\mathrm{O}$ and $\mathrm{C}=\mathrm{C}$ bonding in all the chlorinated films. IRRAS spectra also showed the presence of $\mathrm{C}-\mathrm{Cl}$ bonds in the most chlorinated a-C:H:O:Cl films. Hydration of $\mathrm{Si}-\mathrm{Cl}$ to $\mathrm{Si}$-OH occurs in the $\mathrm{a}-\mathrm{C}: \mathrm{H}: \mathrm{Si}: \mathrm{O}: \mathrm{Cl}$ films. As revealed by Energy-dispersive $\mathrm{X}$-ray spectroscopy (EDS) the $\mathrm{Cl}$ content increases and the $\mathrm{O}$ content decreases as $\mathrm{C}_{\mathrm{Cl}}$ increases. Under the range of conditions used, $[\mathrm{Cl}]$ reached maxima of $\sim 32$ at.\% and 25 at.\%, respectively, for the series of a-C:H:O:Cl and the a-C:H:Si:O:Cl films. For the a$\mathrm{C}: \mathrm{H}: \mathrm{Si}: \mathrm{O}: \mathrm{Cl}$ films the $\mathrm{Si}$ content decreases with increasing $\mathrm{C}_{\mathrm{Cl}}$. Optical properties were calculated from Ultraviolet-visible near infrared spectral data. Refractive indices varied between $\sim 1.52$ and 1.78, depending on $\mathrm{C}_{\mathrm{Cl}}$. The Tauc gaps can be selected by a suitable choice of $\mathrm{C}_{\mathrm{Cl}}$ in the range of roughly 1.3 $-2.6 \mathrm{eV}$.
\end{abstract}

(c) 2018 Elsevier B.V. All rights reserved.

\section{Introduction}

Over the last few years the chemical structure and composition of chlorinated plasma polymers have been investigated [1-5]. Typically, a-C:H:Cl films produced by Plasma Enhanced Chemical Vapor Deposition (PECVD) exhibit increased deposition rates as, for example, trichloromethane is introduced into the chamber feed together with acetylene [1], propanol [2] or tetramethylsilane [4].

\footnotetext{
* Corresponding author.

E-mail address: steve@sorocaba.unesp.br (S.F. Durrant).

1 POSMAT student.
}

Deposition rates of around $100 \mathrm{~nm} \mathrm{~min}{ }^{-1}$ are typically observed. The chlorine content of the deposited material varies with the deposition conditions, reaching almost 50 at.\% under suitable conditions [1], but only 3 at.\% when tetramethylsilane (TMS) is used as a monomer [4]. Vásquez et al. used plasmas fed pyrrole and thiopene with trichloromethane to produce amorphous films with similar chlorine contents [5]. The majority of the other extant studies deal with the plasma treatment using trichloromethane rather than film deposition [6-8].

For films produced from $\mathrm{C}_{2} \mathrm{H}_{2}-\mathrm{CHCl}_{3}-\mathrm{Ar}$ mixtures, the chlorinated films contain $\mathrm{CH}, \mathrm{CH}_{3}, \mathrm{C}=\mathrm{C}$ and $\mathrm{C}-\mathrm{Cl}$ structures as revealed by transmission infrared spectroscopy. In all the films deposited from 


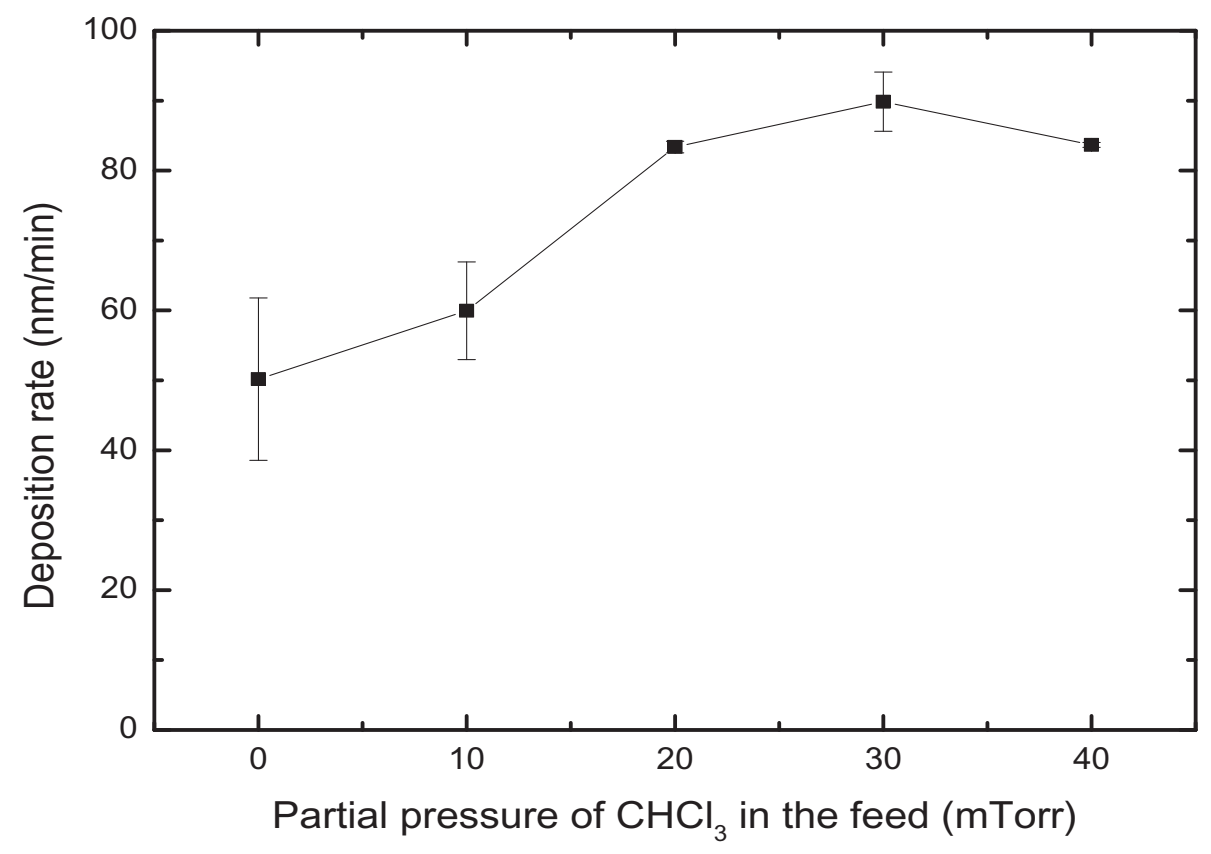

Fig. 1(a). Deposition rate as a function of $\mathrm{C}_{\mathrm{Cl}}$ for the a-C:H:O:Cl films.

$\mathrm{C}_{2} \mathrm{H}_{5} \mathrm{OH}-\mathrm{CHCl}_{3}-\mathrm{Ar}$ mixtures [2], $\mathrm{CH}_{\mathrm{x}}(\mathrm{x}=1$ to 3 ) groups are present, while for the highest partial pressure of $\mathrm{CHCl}_{3}$ used in the feed (40\%), oxygen is present as $\mathrm{OH}$ rather than $\mathrm{C}=\mathrm{O}$. A wide range of groups are observed in films produced from $\mathrm{TMS}-\mathrm{CHCl}_{3}-\mathrm{Ar}$ mixtures [4], including $\mathrm{CH}_{\mathrm{x}}, \mathrm{Si}-\mathrm{CH}, \mathrm{Si}-\mathrm{CH}_{2}$, Si-O-Si and $\mathrm{Si}-\mathrm{CH}_{2}-\mathrm{Si}$. The optical gap tends to rise for a-C: $\mathrm{H}: \mathrm{Cl}$ films as the partial pressure of $\mathrm{CHCl}_{3}$ in the feed is increased [1,2] but, intriguingly, tends to fall with increasing partial pressure of $\mathrm{CHCl}_{3}$ for films deposited from TMS- $\mathrm{CHCl}_{3}-\mathrm{Ar}$ mixtures.

Here we examine the structural and optical properties of a$\mathrm{C}: \mathrm{H}: \mathrm{O}: \mathrm{Cl}$ and a-C:H:Si:O:Cl films deposited from $\mathrm{C}_{2} \mathrm{H}_{4}-\mathrm{CHCl}_{3}-\mathrm{O}_{2}$ and HMDSO- $\mathrm{CHCl}_{3}-\mathrm{O}_{2}$ mixtures. Films were deposited at different partial pressures of $\mathrm{CHCl}_{3}$ in the chamber feed, $\mathrm{C}_{\mathrm{Cl}}$. The motivation of the study is twofold: first, to investigate the range of the chemical structure and composition of such films on which there is little extant literature; second, to explore the dependencies of the optical properties on the film composition and structure.

\section{Experimental}

\subsection{Film deposition}

Films were produced in a $13.56 \mathrm{MHz}$ PECVD system, consisting of a cylindrical stainless-steel chamber containing two circular, horizontal electrodes. The lower electrode was fed power from a Tokyo Hy-Power, MB-300 supply via a capacitance matching box;

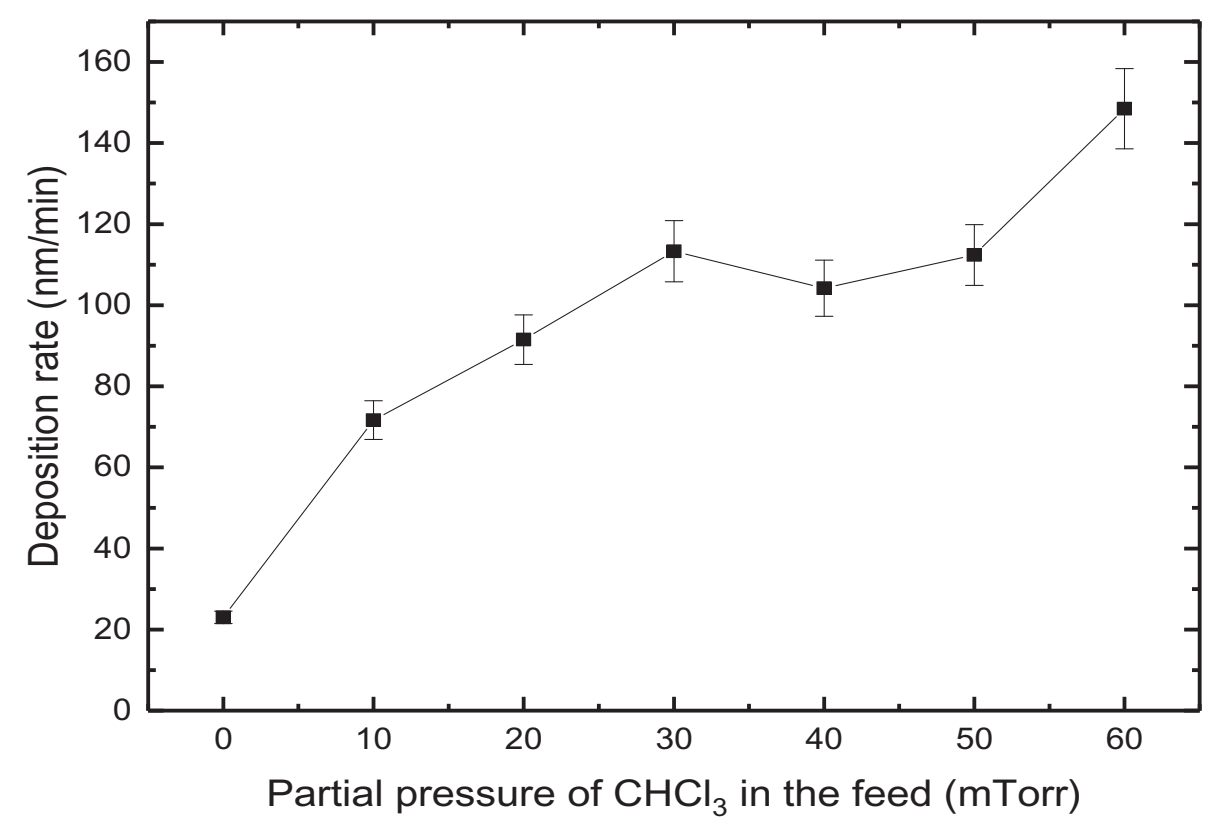

Fig. 1(b). Deposition rate as a function of $\mathrm{C}_{\mathrm{Cl}}$ for the a-C:H:Si:O:Cl films. 


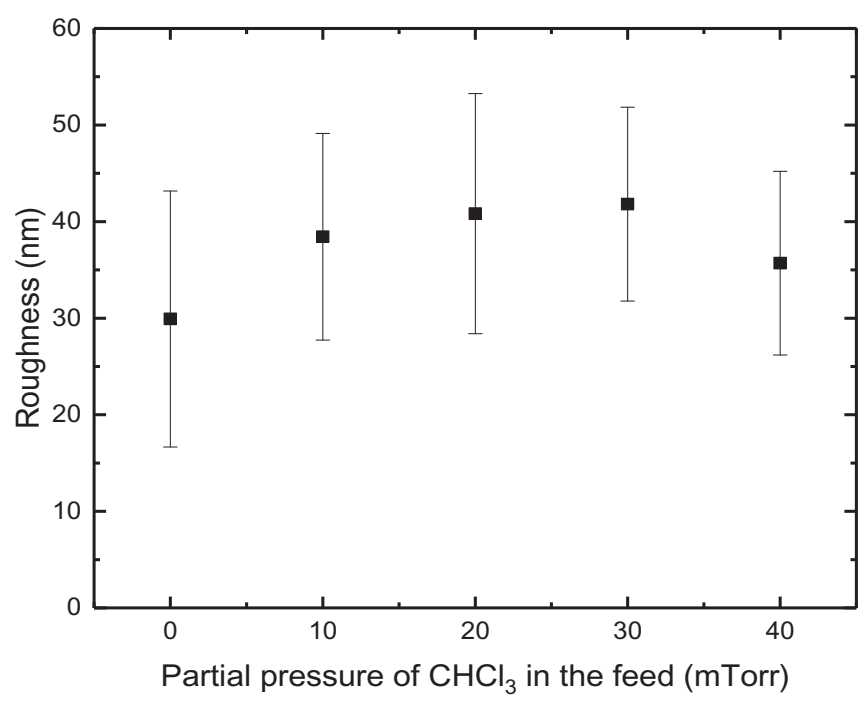

Fig. 2(a). Roughness as a function of $\mathrm{C}_{\mathrm{Cl}}$ for the a-C:H:O:Cl films.

the upper electrode was earthed. Pressures were measured using an Agilent Pirani gauge.

For the series of films deposited from $\mathrm{C}_{2} \mathrm{H}_{4}$, fixed partial pressures of $50 \mathrm{mTorr}$ of $\mathrm{C}_{2} \mathrm{H}_{4}$ and $3 \mathrm{mTorr}$ of $\mathrm{O}_{2}$ were used. The partial pressure of $\mathrm{CHCl}_{3}$ was varied from 0 to 40 mTorr. For the series deposited from hexamethyldisiloxane (HMDSO), a fixed partial pressure of 42 mTorr of HMDSO and 8 mTorr of $\mathrm{O}_{2}$ were used. The partial pressure of $\mathrm{CHCl}_{3}$ was varied from 0 to 60 mTorr. Thus the principal system parameter was the partial pressure of $\mathrm{CHCl}_{3}$ in the feed, $\mathrm{C}_{\mathrm{Cl}}$. An applied power of $60 \mathrm{~W}$ and a deposition time of $15 \mathrm{~min}$ were used throughout.

\subsection{Film characterization}

Film thicknesses were determined from step-height profiles measured using a profilometer (Veeco, Dektak 150). The step-

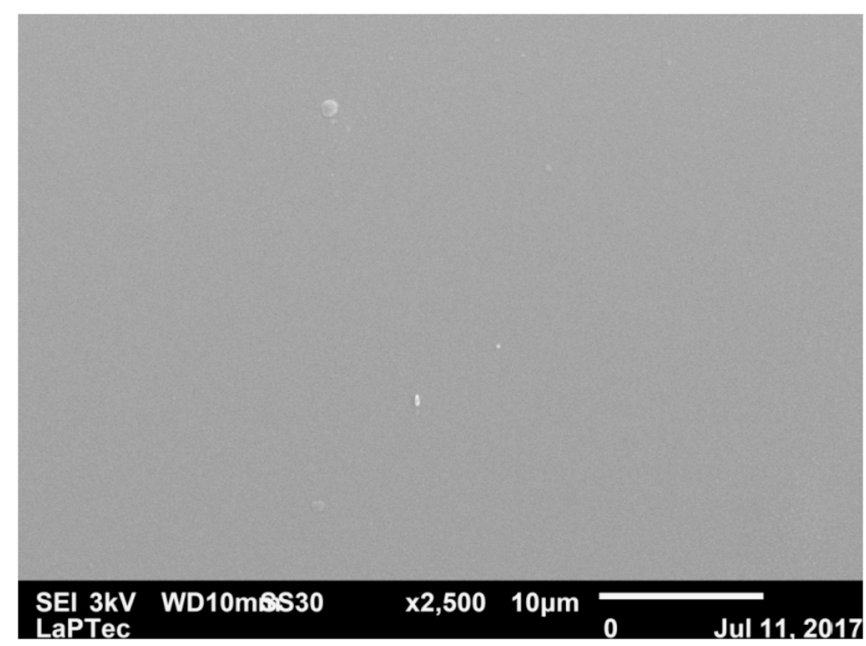

Fig. 2(c). Micrograph of the a-C:H:O:Cl film deposited at $\mathrm{C}_{\mathrm{Cl}}=30$ mTorr.

heights were produced by depositing a film on a glass slide partially covered by a tape, and then removing the tape. Deposition rates were calculated from film thickness and deposition time. Surface roughness, $R_{a}$, was calculated from the measurement of heights of ten points taken from three linear surface scans.

Infrared reflection absorption spectroscopy (IRRAS) of films deposited onto polished stainless-steel substrates was undertaken using a Jasco FTIR-410 spectrophotometer over the 4000 to $400 \mathrm{~cm}^{-1}$ wavenumber range. For each spectrum 128 scans were accumulated. The typical resolution was $4 \mathrm{~cm}^{-1}$.

The chemical composition of the films was quantified by Energy Dispersive X-ray Spectrometry (EDS) using an accessory attached to a Jeol JSM-6010 Scanning Electron Microscope. Surface morphology was examined by taking micrographs using the secondary electron signal at an accelerating voltage of $3 \mathrm{kV}$.

Surface contact angle, $\theta$, measurements were made using a Ramé-Hart 100-00 goniometer. Surface angles were measured ten times for each of three drops of deionized water $(0.2 \mu \mathrm{L})$ placed at

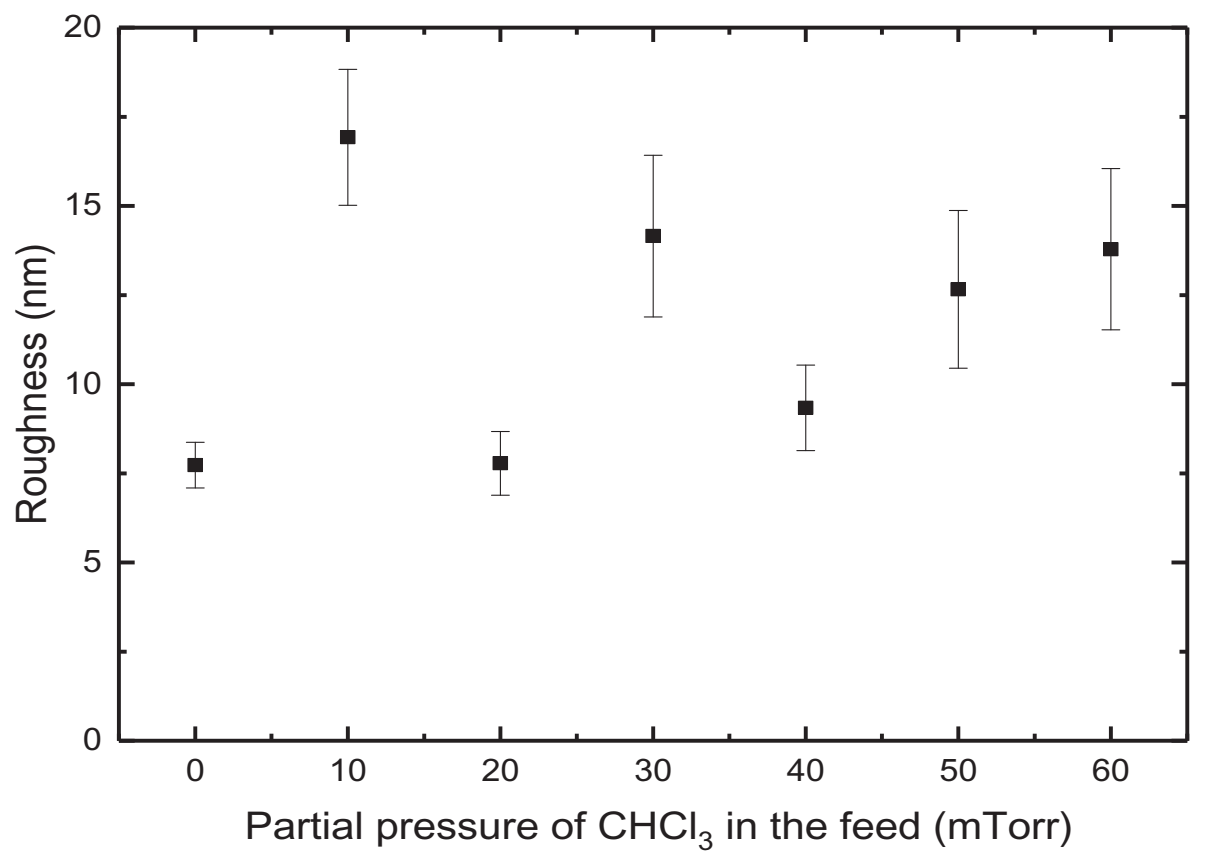

Fig. 2(b). Roughness as a function of $\mathrm{C}_{\mathrm{Cl}}$ for the a-C:H:Si:O:Cl films. 


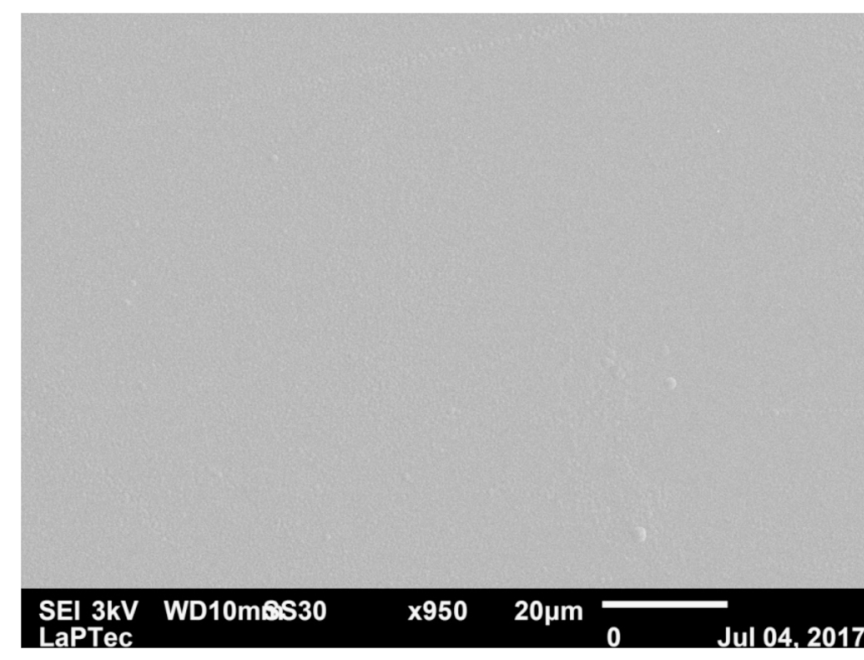

Fig. 2(d). Micrograph of the a-C:H:Si:O:Cl film deposited at $\mathrm{C}_{\mathrm{Cl}}=30$ mTorr.

different points on the sample surface.

Film optical properties, refractive index, n, absorption coefficient, $\alpha(\mathrm{E})$, and optical gap, $\mathrm{E}_{\mathrm{Tau}}$, were determined from film thickness and Ultraviolet-visible near infrared (UVS) spectral data. Procedures given by Cisneros were used to calculate $n$ e $\alpha(E)$ [9]. Although the deposited material is not crystalline, the Tauc model [10] was successfully applied to determine the optical gap. Transmission UVS data were obtained using a Perkin Elmer Lambda 750 double-beam spectrophotometer from films deposited onto quartz substrates.

\section{Results and discussion}

Fig. 1(a, b) shows the deposition rate, $\mathrm{R}$, as a function of the partial pressure of $\mathrm{CHCl}_{3}$ in the plasma feed, $\mathrm{C}_{\mathrm{Cl}}$, in the $\mathrm{C}_{2} \mathrm{H}_{4}$ and TMS plasma feed, respectively. Inclusion of $\mathrm{CHCl}_{3}$ in the feed increases $\mathrm{R}$, which has a characteristic form, rising with $\mathrm{C}_{\mathrm{Cl}}$, probably owing to reactions producing $\mathrm{CH}_{\mathrm{x}}$ film precursors. At high $\mathrm{C}_{\mathrm{Cl}}$ relatively great concentrations of $\mathrm{Cl}$ may be produced and cause etching, thus decreasing R. Similar behavior is observed in other monomer-halogen plasmas, such as $\mathrm{C}_{2} \mathrm{H}_{2}-\mathrm{SF}_{6}$ [11]. The curve shown in Fig. 1(a) exhibits this feature.

Surface roughness as a function of $\mathrm{C}_{\mathrm{Cl}}$ is shown in Fig. 2(a, b). For the films deposited from $\mathrm{C}_{2} \mathrm{H}_{4}-\mathrm{CHCl}_{3}-\mathrm{O}_{2}$ plasmas mixtures the roughness is not a strong function of $\mathrm{C}_{\mathrm{Cl}}$, and is typically about $40 \mathrm{~nm}$. No systematic variation is shown by the roughness of the films deposited from TMS- $\mathrm{CHCl}_{3}-\mathrm{O}_{2}$ plasmas, the absolute values being around $20 \mathrm{~nm}$. The roughnesses observed here (Fig. 2(a)) are similar to those observed elsewhere for plasma-deposited a$\mathrm{C}: \mathrm{H}: \mathrm{O}: \mathrm{Cl}$ films [3].

As the film surfaces do not show significant variations in morphology, Fig. 2(c, d) shows typical micrographs of a-C:H:O:Cl and a-C:H:Si:O:Cl films deposited at a $\mathrm{C}_{\mathrm{Cl}}$ of 30 mTorr. The visual smoothness of the images agrees with the low reported roughnesses.

Fig. 3(a, b) shows transmission infrared spectra of the films of the two series. Possible attributions of the absorption bands are given in the figure. For the a-C:H:O:Cl series (Fig. 3(a)), there are absorptions at $\sim 2900$ owing to $-\mathrm{CH}$, at $\sim 1700 \mathrm{~cm}^{-1}$ owing to $\mathrm{C}=\mathrm{O}$, at $\sim 1620 \mathrm{~cm}^{-1}$ owing to $\mathrm{C}=\mathrm{C}$, and $\sim 1250 \mathrm{~cm}^{-1}$ owing to $\mathrm{C}-\mathrm{O}$. At a $\mathrm{C}_{\mathrm{Cl}}$ of $\geq 30 \%$, a small weak band emerges at $\sim 770 \mathrm{~cm}^{-1}$ owing to $\mathrm{C}-\mathrm{Cl}$. Thus some $\mathrm{C}=\mathrm{C}$ is always preserved from the monomer, but some substitution by oxygen for carbon also occurs in all of the films of

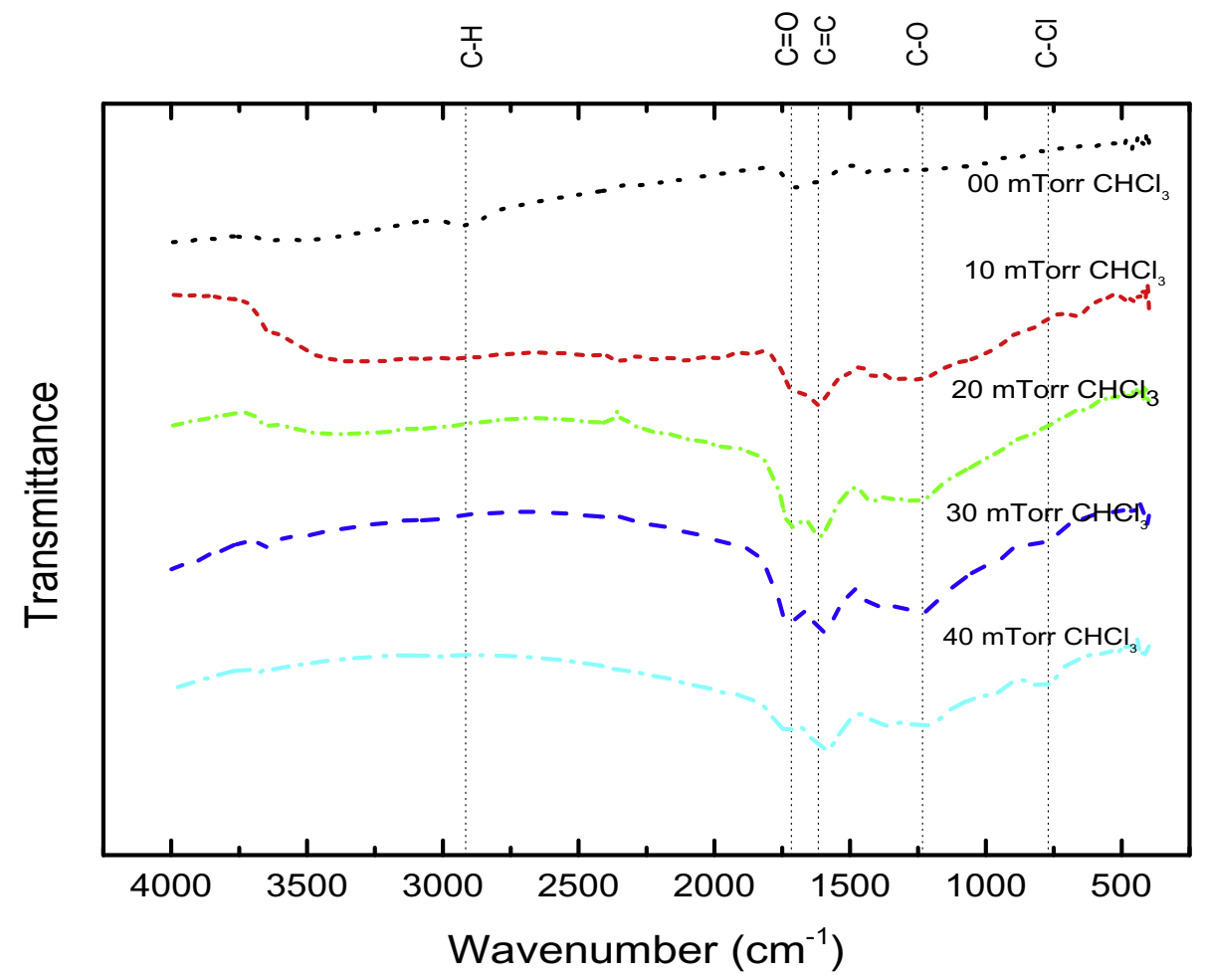

Fig. 3(a). Infrared spectra of the a-C:H:O: $\mathrm{Cl}$ films produced at different $\mathrm{C}_{\mathrm{Cl}}$. 


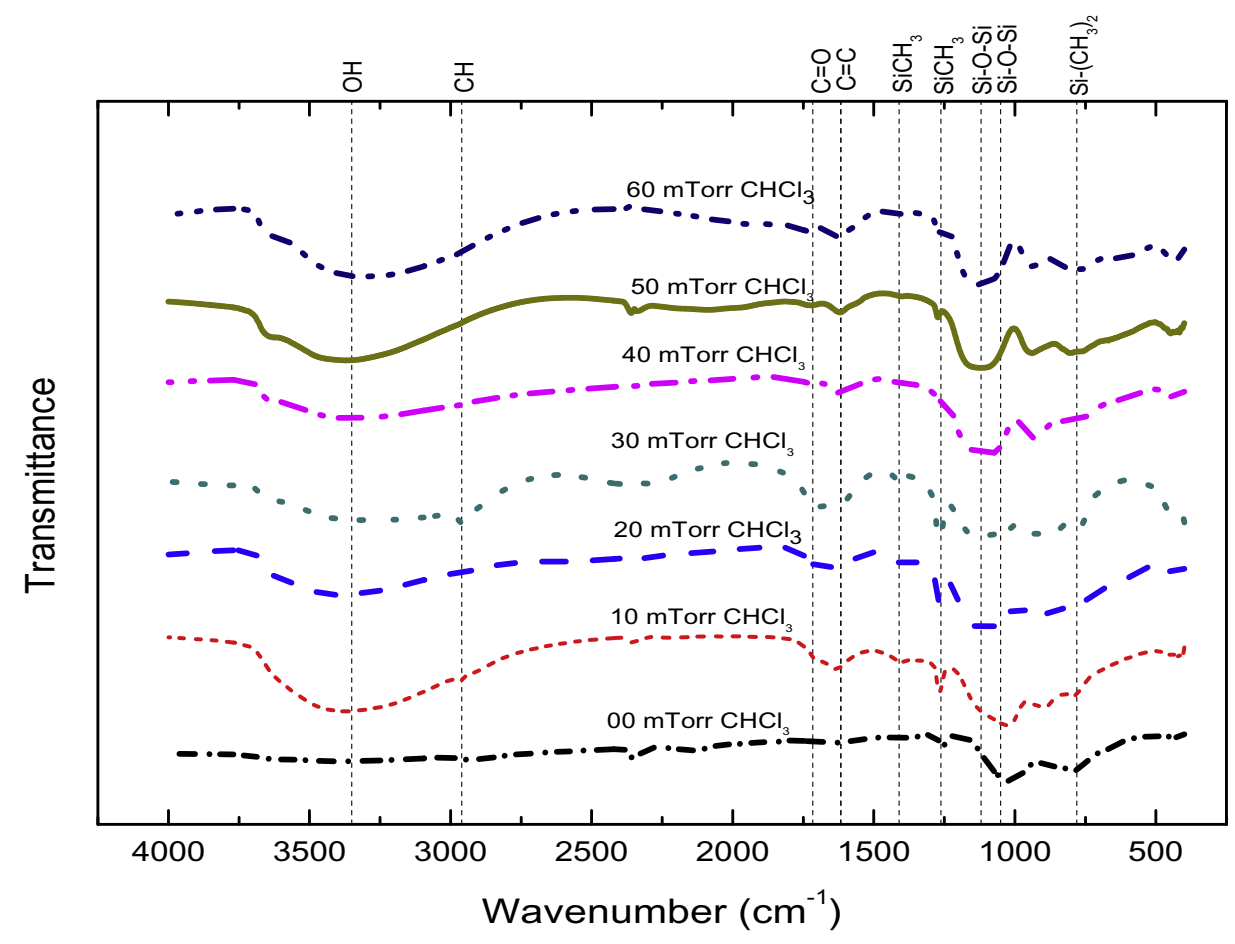

Fig. 3(b). Infrared spectra of the a-C:H:Si:O:Cl films produced at different $\mathrm{C}_{\mathrm{Cl}}$.

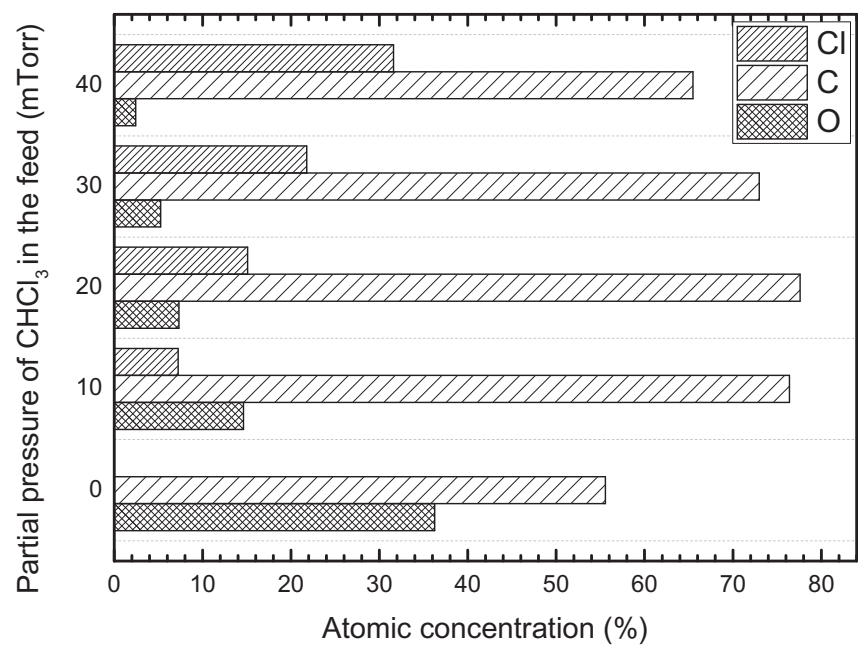

Fig. 4(a). Elemental concentrations of the a-C:H:O:Cl films produced at different $\mathrm{C}_{\mathrm{Cl}}$

this series. Strong fragmentation is indicated by the lack of absorptions at $\sim 2900 \mathrm{~cm}^{-1}$ attributable to $\mathrm{CH}$ groups.

The spectra of Fig. 3(b) (a-C:H:Si:O:Cl films) are similarly lacking absorptions due to $\mathrm{CH}$. Possible attributions of the remaining peaks are given in the figure. In contrast to the spectra of the a-C:H:O:Cl films, a prominent absorption at around $3400 \mathrm{~cm}^{-1}$ is attributed to the present of hydroxyl groups in all of the films, except that not containing chlorine. A possible mechanism for the production of $\mathrm{Si}$ $\mathrm{OH}$ is the hydration of weak $\mathrm{Si}-\mathrm{Cl}$ bonds, liberating $\mathrm{HCl}$. In all the chlorinated films of this series there are absorptions owing to $\mathrm{C}=\mathrm{O}$ and $\mathrm{C}=\mathrm{C}$ groups. Neither of these groups is present in any of the feed molecules; therefore only multiple-step reactions can produce them. The Si-O-Si structure is present in the HMDSO monomer, and is reserved to some extent in all of the films. As the absorption band at $\sim 770 \mathrm{~cm}^{-1}$ is present in the spectrum of the unchlorinated film

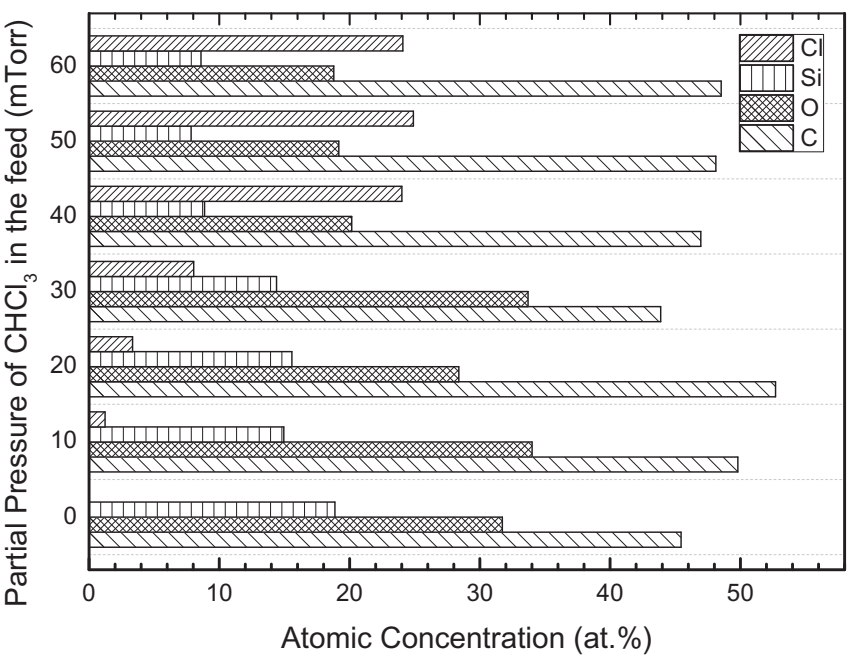

Fig. 4(b). Elemental concentrations of the a-C:H:Si:O:Cl films produced at different $\mathrm{C}_{\mathrm{Cl}}$.

and diminishes as $\mathrm{C}_{\mathrm{Cl}}$ increases, it is attributed to $\mathrm{Si}-\left(\mathrm{CH}_{3}\right)_{2}$ [12] rather than $\mathrm{C}-\mathrm{Cl}$.

Fig. 4(a, b) shows the elemental concentrations in the films as determined using EDS. As $\mathrm{H}$ cannot be determined the $\mathrm{H}$ content has been ignored. For the a-C:H:O: $\mathrm{Cl}$ films the $\mathrm{Cl}$ content increases and the oxygen content decreases as $\mathrm{C}_{\mathrm{Cl}}$ is increased. The relative carbon content is always greater than $\sim 55$ at.\%, and is greater for the chlorinated films.

For the a-C:H:Si:O:Cl films (Fig. 4(b)) the oxygen content also tends to fall and the chlorine content rise with increasing $\mathrm{C}_{\mathrm{Cl}}$. The relative silicon content falls as $\mathrm{C}_{\mathrm{Cl}}$ increases. Thus chlorine incorporation increases with increasing supply of $\mathrm{Cl}$ in the plasma at the expense of $\mathrm{O}$. The [Si] is reduced to half its value as $\mathrm{C}_{\mathrm{Cl}}$ increases from 0 to 60 mTorr. 


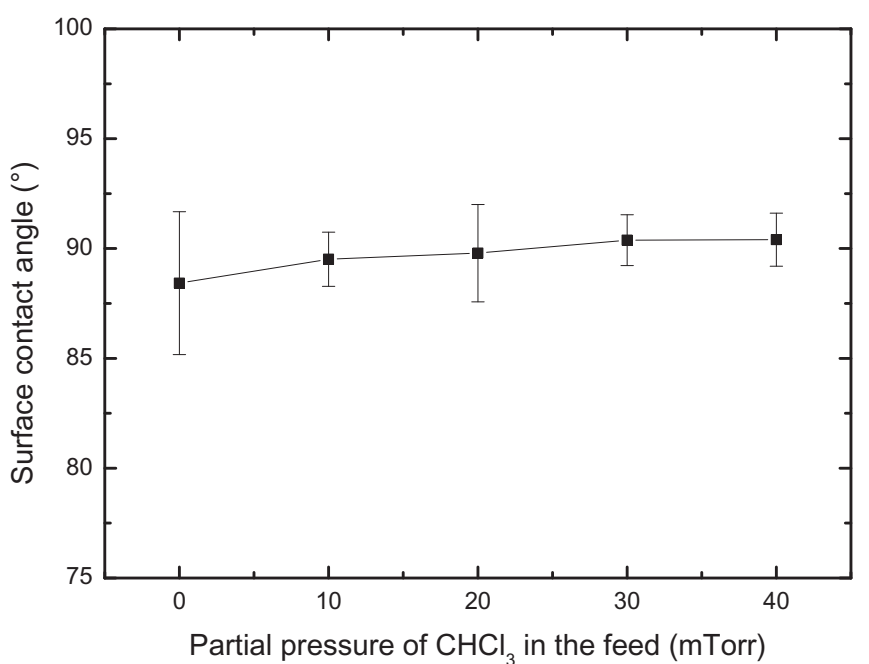

Fig. 5(a). Surface contact angle as a function of $\mathrm{C}_{\mathrm{Cl}}$ for the a-C:H:O:Cl films.

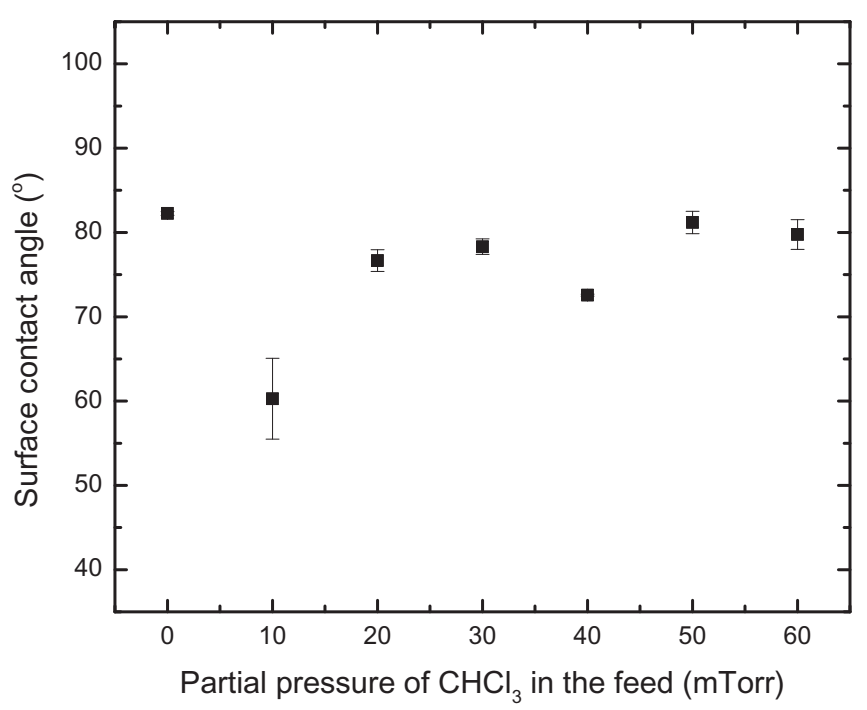

Fig. 5(b). Surface contact angle as a function of $\mathrm{C}_{\mathrm{Cl}}$ for the a-C:H:Si:O:Cl films.

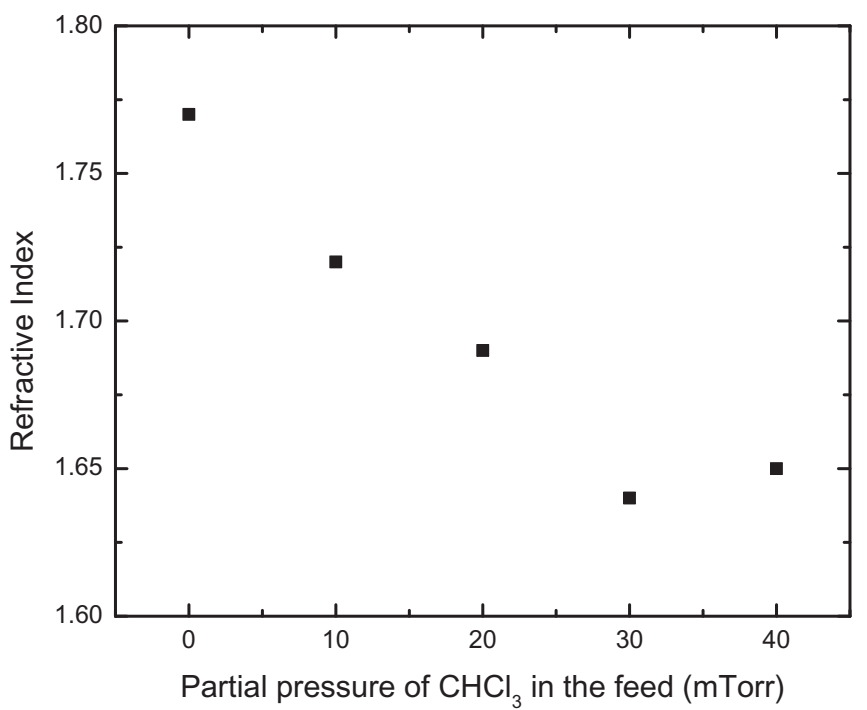

Fig. 6(a). Refractive index as a function of $\mathrm{C}_{\mathrm{Cl}}$ for the a-C:H:O:Cl films.

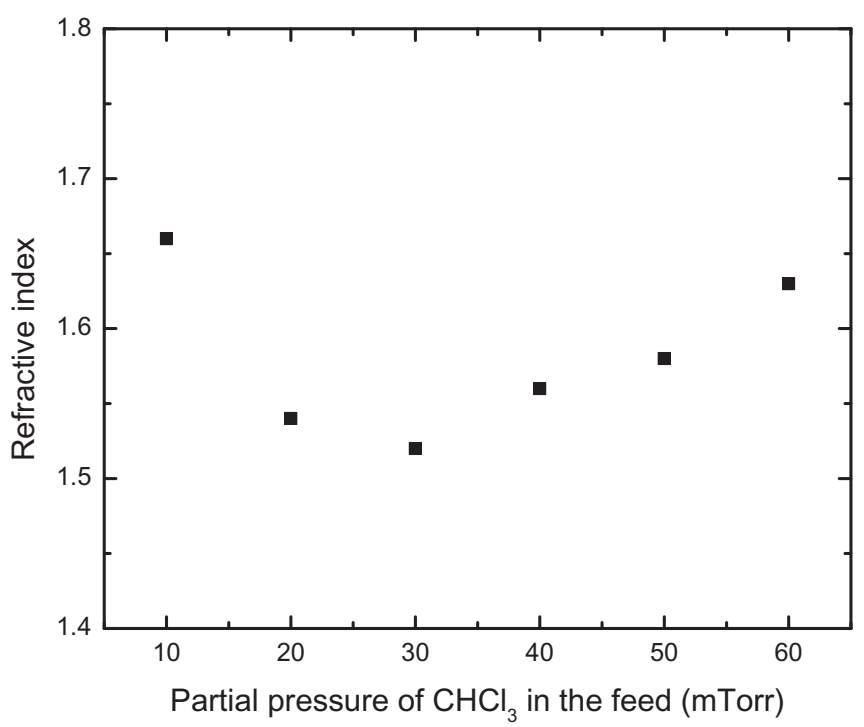

Fig. 6(b). Refractive index as a function of $\mathrm{C}_{\mathrm{Cl}}$ for the a-C:H:Si:O:Cl films.

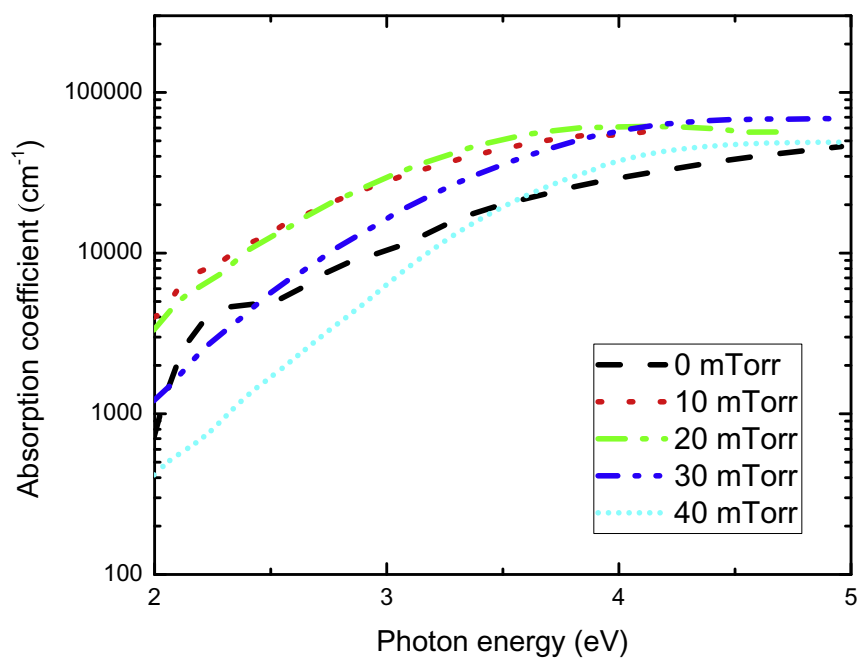

Fig. 7(a). Absorption coefficient as a function of photon energy for the a-C:H:O:Cl films grown at different $\mathrm{C}_{\mathrm{Cl}}$

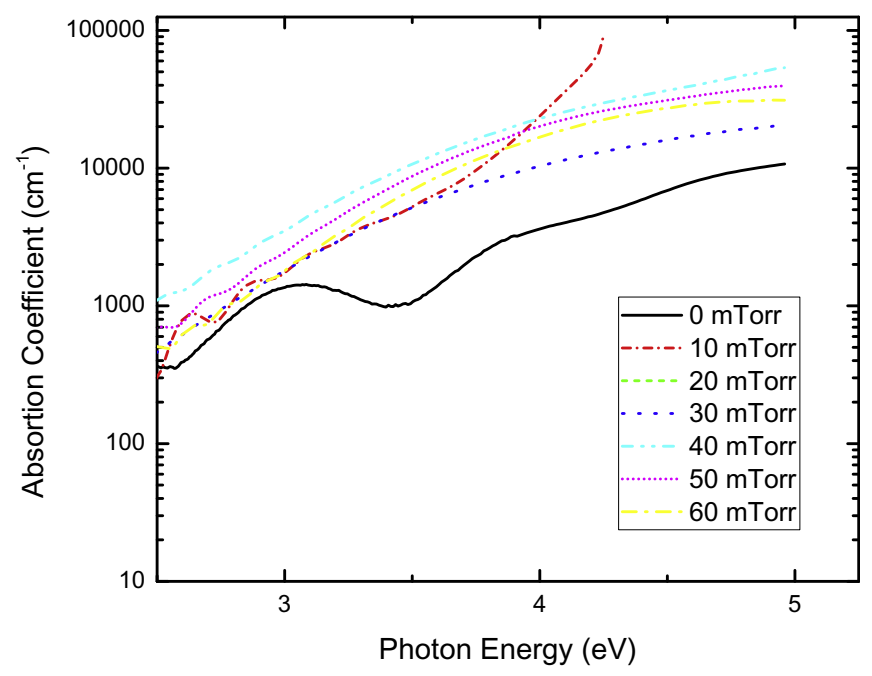

Fig. 7(b). Absorption coefficient as a function of photon energy for the a-C:H:Si:O:Cl films grown at different $\mathrm{C}_{\mathrm{Cl}}$. 


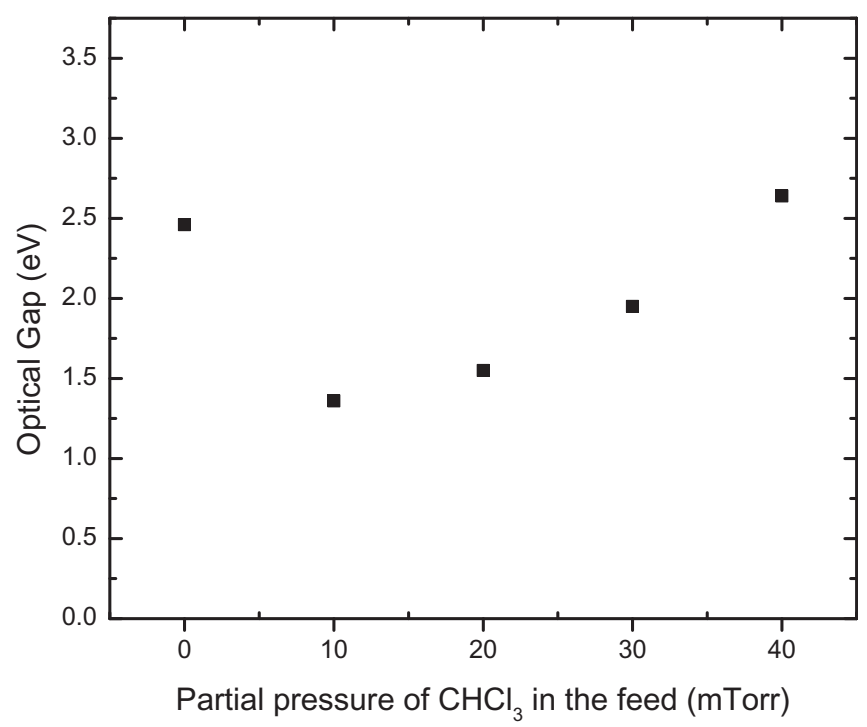

Fig. 8(a). Tauc gap as a function of $\mathrm{C}_{\mathrm{Cl}}$ for the a-C:H:O:Cl films.

The surface contact angle, $\theta$, is shown as a function of $\mathrm{C}_{\mathrm{Cl}}$ for the $\mathrm{a}-\mathrm{C}: \mathrm{H}: \mathrm{O}: \mathrm{Cl}$ and a-C:H:Si:O:Cl films in Fig. 5(a) and 5(b), respectively. In neither case is there a strong dependence of $\theta$ on $\mathrm{C}_{\mathrm{Cl}}$. For the a-C: $\mathrm{H}: \mathrm{O}: \mathrm{Cl}$ films the absolute values $\left(\sim 90^{\circ}\right)$ are similar to those obtained for a-C:H:O:Cl films produced from $\mathrm{C}_{2} \mathrm{H}_{2}-\mathrm{CHCl}_{3}-\mathrm{Ar}$ plasmas [1]. A surface contact angle of $\sim 82^{\circ}$ was also reported for a$\mathrm{C}: \mathrm{H}: \mathrm{Cl}$ plasma films deposited from $\mathrm{C}_{2} \mathrm{H}_{2}-\mathrm{CHCl}_{3}$ mixtures [13].

The contact angle depends on surface roughness, chemical composition and structure. As shown above (Fig. 2(a and b)) roughness is a weak function of $\mathrm{C}_{\mathrm{Cl}}$. Despite all the structural and compositional changes observed as a function of $\mathrm{C}_{\mathrm{Cl}}$, the overall effect on $\theta$ is small.
Fig. 6(a,b) shows $\mathrm{n}$ for the a-C:H:O:Cl and a-C:H:Si:O:Cl films, respectively, as a function of $\mathrm{C}_{\mathrm{Cl}}$. In both cases $\mathrm{n}$ tends to fall as $\mathrm{C}_{\mathrm{Cl}}$ increases but then to increase from the minimum value for $\mathrm{C}_{\mathrm{Cl}}$ beyond about 30 mTorr. The form is similar although not identical to that observed for the refractive index of a-C:H:O:Cl films obtained from $\mathrm{C}_{2} \mathrm{H}_{2}-\mathrm{CHCl}_{3}-\mathrm{Ar}$ plasmas [1]. Also, the range of values obtained here is compatible with the range observed in the previous study. Similarly, the magnitude of n previously determined for a plasma-deposited a-C: $\mathrm{H}: \mathrm{Cl}$ film [13], $1.59 \pm 0.04$, lies in the range observed here (Fig. 8(a)). The complex structural and compositional changes impede elucidation of the mechanisms responsible for the observed dependence of $\mathrm{n}$ on $\mathrm{C}_{\mathrm{Cl}}$. For the a-C:H:O:Cl films, for example, based on the IRRAS spectra $[\mathrm{CH}]$ decreases while [CCl] increases with increasing $\mathrm{C}_{\mathrm{Cl}}$. Then too, as the EDS analyses revealed, [O] decreases and $[\mathrm{Cl}]$ increases with increasing $\mathrm{C}_{\mathrm{Cl}}$. Hence both he polarizability of the bonds and their densities change, thereby altering $\mathrm{n}$.

Fig. 7(a,b) shows $\alpha(E)$, the absorption coefficient, as a function of the photon energy, E, for the two series of films. From such data Tauc plots were produced (not shown). Extrapolation of linear portions of such plots allows the optical gaps to be calculated. The results are shown in Fig. 8(a,b) for the a-C:H:O:Cl and a-C:H:Si:O:Cl films. Both curves have a similar shape. A Tauc gap of $2.75 \mathrm{eV}$, measured for a-C:H:Cl plasma films [13], is consistent with the range of values shown in Fig. 8(a).

The gaps initially fall with increasing $\mathrm{C}_{\mathrm{Cl}}$ but then increase for $\mathrm{C}_{\mathrm{Cl}}$ $\geq 10 \%$. Rising trends in $\mathrm{E}_{\mathrm{Tau}}$ as a function of $\mathrm{C}_{\mathrm{Cl}}$ may also be qualitatively explained as the result of changing bond types and densities. For example, for the a-C:H:Si:O:Cl films a shift from structures such as $\mathrm{Si}-\mathrm{O}-\mathrm{Si}$ and $\mathrm{Si}\left(\mathrm{CH}_{3}\right)_{2}$ to $\mathrm{Si}-\mathrm{OH}$ and $\mathrm{C}-\mathrm{Cl}$, together with a decrease in [Si] and [O] can alter optical absorption and thereby the gap. Changes in types of bond imply changes in bond length. For example, $\mathrm{Si}-\mathrm{CH}_{3}$ and $\mathrm{Si}-\mathrm{O}$ have bond lengths of $189.9 \mathrm{pm}$ [14] and $160 \mathrm{pm}$ [15], respectively.

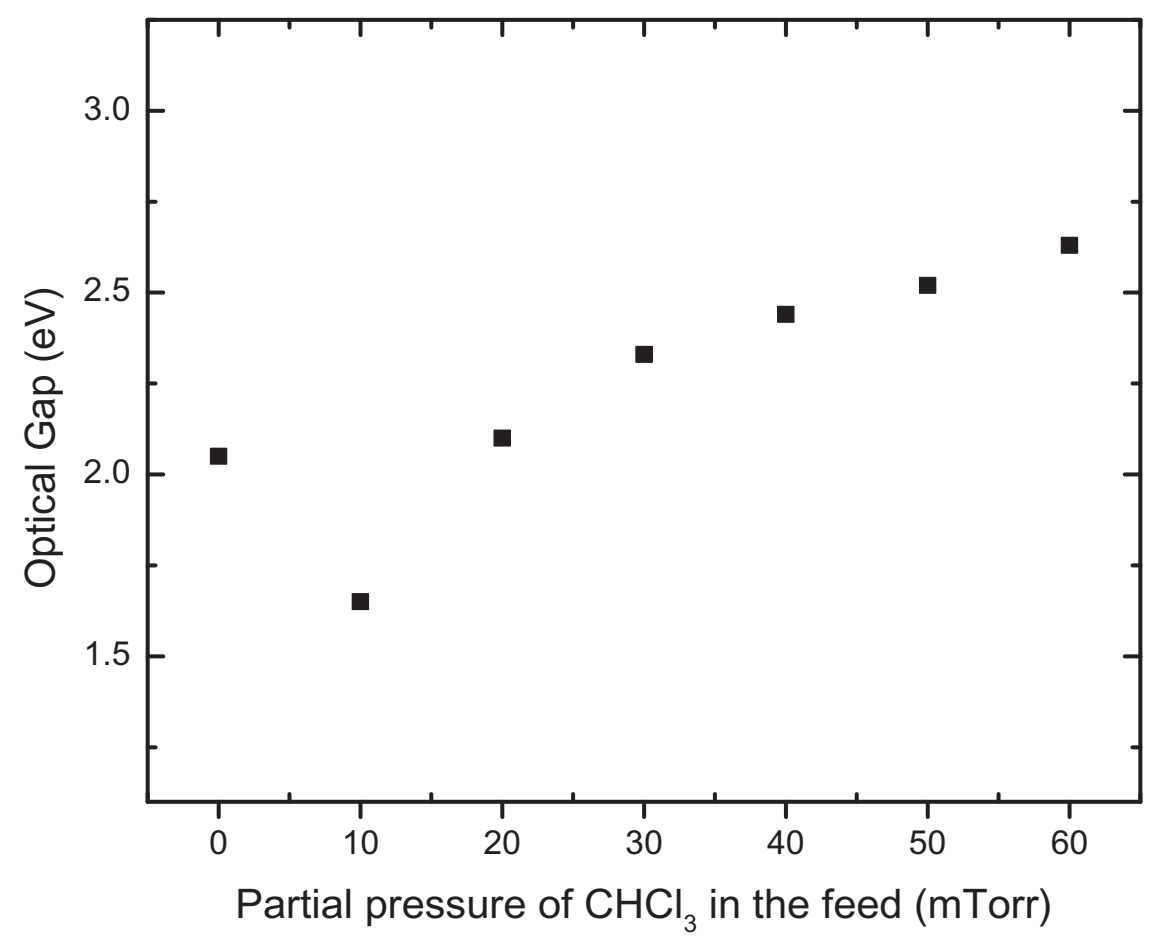

Fig. 8(b). Tauc gap as a function of $\mathrm{C}_{\mathrm{Cl}}$ for the a-C:H:Si:O:Cl films. 


\section{Conclusions}

PECVD has been used to produce a-C:H:O: $\mathrm{Cl}$ and a-C:H:Si:O:Cl films at different partial pressures of $\mathrm{CHCl}_{3}$ in the feed. Deposition rates range from $\sim 20$ to $\sim 140 \mathrm{nmmin}^{-1}$, and tend to increase with increasing $\mathrm{C}_{\mathrm{Cl}}$. There is little extant literature on the structure and composition of such films, especially of the a-C:H:Si:O:Cl type. Infrared analyses reveal the presence of $\mathrm{C}=\mathrm{O}, \mathrm{C}=\mathrm{C}, \mathrm{C}-\mathrm{O}$ and $\mathrm{C}-\mathrm{Cl}$ structures in the a-C:H:O: $\mathrm{Cl}$ films, i.e. the films deposited with nonzero values of $\mathrm{C}_{\mathrm{Cl}}$. The chlorinated films are poor in hydrogen. For the a-C:H:Si:O:Cl films, silicon-containing functionalities, such as $\mathrm{Si}-\mathrm{O}-\mathrm{Si}$ and $\mathrm{Si}-\left(\mathrm{CH}_{3}\right)_{2}$ are present. Hydroxyl groups are present in the chlorinated silicon-containing films. As revealed by EDS, all the films tend to become more chlorinated and less oxygenated as $\mathrm{C}_{\mathrm{Cl}}$ is increased. Maximum chlorine contents of 32 at.\% and 25 at.\%, respectively, were obtained for the a-C:H:O:Cl and a-C:H:Si:O:Cl. While film surface roughnesses did not exceed $50 \mathrm{~nm}$, water contact angles were, respectively, $\sim 90^{\circ}$ and $\sim 75^{\circ}$.

The refractive indices of the deposited material can be controlled between about 1.65 and 1.77 for the a-C:H:O:Cl films. Similarly, $\mathrm{n}$ of the a-C:H:Si:O:Cl films may be selected in the range of about $1.5-1.67$. Tauc gaps fall roughly in the $1.5-2.5 \mathrm{eV}$ range, which is consistent with the few values reported in the directlyrelated literature.

\section{Acknowledgements}

The authors thank FAPESP (2014/21594-9) for financial support. Two of us, ICF and TVH, gratefully acknowledge support via scientific initiation grants from CNPq (PIBIC) and UNESP, respectively. MKMA, gratefully acknowledges the support of CAPES.

\section{References}

[1] R. Turri, C.U. Davanzo, W. Schreiner, J.H. Dias da Silva, M.B. Appolinario, S.F. Durrant, Structural and optical properties of chlorinated plasma polymers, Thin Solid Films 52 (2011) 1442-1445.

[2] D. Rossi, W.H. Schreiner, S.F. Durrant, Characterization of amorphous hydrogenated chlorinated plasma polymers, Surf. Coating. Technol. 289 (2016) $118-123$.

[3] R.G. Turri, M.K.M. Amorim, T.V. Hadich, I.C. Fernandes, G.F. Fernandes, D. Rossi, E.C. Rangel, S.F. Durrant, Effects of aging on chlorinated plasma polymers, Mater. Res. 20 (4) (2017) 862-865.

[4] D. Rossi, R. Landers, J.R.R. Bortoleto, S.F. Durrant, Characterization of PECVD aC: H:Si:O: Cl films, J. Vac. Sci. Technol., A 35 (4) (2017), 04D103-1-04D103-8.

[5] M. Vásquez, G.J. Cruz, M.G. Olayo, T. Timoshina, J. Morales, R. Olayo, Chlorine dopants in plasma synthesized heteroaromatic polymers, Polymer 47 (2006) 7864-7870.

[6] N. Inagaki, S. Tasaka, M. Imai, Hydrophilic surface modification of polypropylene films by $\mathrm{CCl}_{4}$ plasma, J. Appl. Polym. Sci. 48 (11) (1993) 1963-1972.

[7] N. Inagaki, S. Tasaka, Y. Suzuki, J Surface chlorination of polypropylene film by CHCI 3 plasma, J. Appl. Polym. Sci. 51 (13) (1994) 2131-2137.

[8] D.J. Upadhyay, N.V. Bhat, Surface modification and characterization of dichloromethane plasma treated polypropylene film, Plasma Polym. 8 (4) (2003) 237-257.

[9] J.I. Cisneros, Optical characterization of dielectric and semiconductor thin films by use of transmission data, Appl. Optic. 37 (22) (1998) 5262-5270.

[10] J. Tauc, in: F. Abeles (Ed.), Optical Properties of Solids, North-Holland Amsterdam, 1972 (Chapter 5).

[11] S.F. Durrant, R.P. Mota, M.A. Bica de Moraes, Relationships between the plasma environment and composition and optical properties of plasmapolymerized thin films produced in rf discharges of $\mathrm{C}_{2} \mathrm{H}_{2}-\mathrm{SF}_{6}$ mixtures, J. Appl. Phys. 71 (1) (1992) 448-455.

[12] A. Heilmann, in: Polymer Films with Embedded Metal Nanoparticles, Springer-Verlag, Berlin, 2003, p. 18.

[13] R.E. Turri, R.M. Santos, E.C. Rangel, N.C. da Cruz, J.R.R. Bortoleto, J.H. Dias da Silva, C.A. Antonio, S.F. Durrant, Optical, mechanical and surface properties of amorphous carbonaceous carbon thin films obtained by plasma enhanced chemical vapor deposition and plasma immersion ion implantation and deposition, Appl. Surf. Sci. 280 (2013) 474-481.

[14] G. Fritz, E. Matern, Carbosilanes: Synthesis and Reactions, Verlag, Berlin, 1986, p. 231.

[15] W.H. Baur, Silicon-oxygen bond lengths, bridging angles Si-O-Si and synthetic low tridymite, Acta Crystallogr. B33 (1977) 2615-2619. 